\title{
МОДЕЛЬ УПРАВЛЕНИЯ КОРПОРАТИВНЫМИ ВЫЧИСЛИТЕЛЬНЫМИ РЕСУРСАМИ ОБРАЗОВАТЕЛЬНОГО КОМПЛЕКСА
}

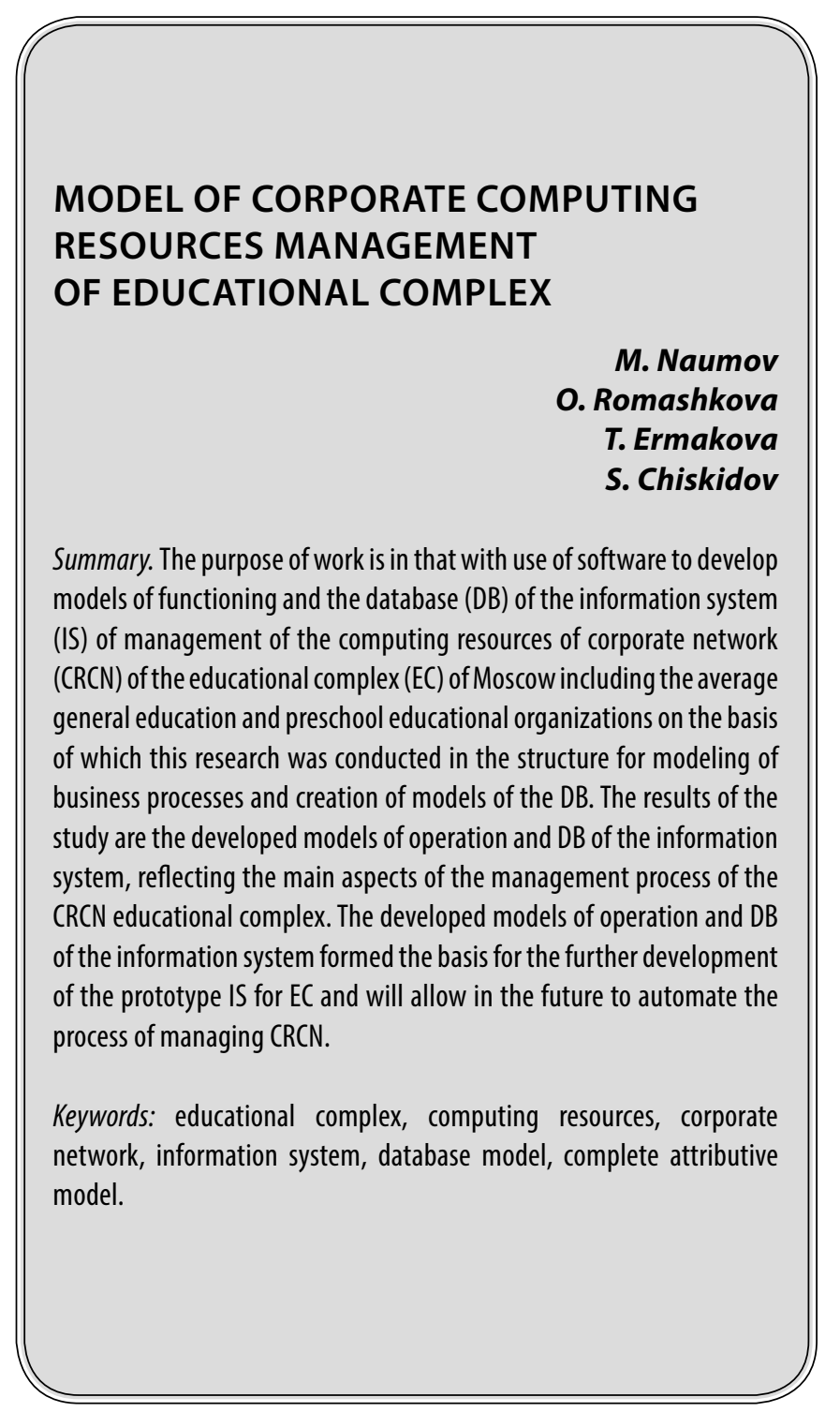

\section{Введение}

$\mathbf{H}$ а сегодняшний день в образовательных комплексах Москвы, включающих в свой состав средние общеобразовательные и дошкольные образовательные организации, перед административно-управленческим персоналом и педагогическими работниками остро стоит проблема автоматизации процесса управления ВРКС, которая до сих пор является нерешенной [1]. В процессе ведения учета ВРКС,
Наумов Максим Александрович

Аспирант, ГАОУ ВО «Московский городской педагогический университет (МГПУ)» manaumoo@yandex.ru

Ромашкова Оксана Николаевна Д.m.н., nрофессор, ГАОУ ВО «Московский городской педагогический университет (МГПУ)»

ox-rom@yandex.ru

Ермакова Татьяна Николаевна

К.т.н., дочент, ГАОУ ВО «Московский городской педагогический университет (МГПУ)» ermaktat@bk.ru

Чискидов Сергей Васильевич K.т.н., дочент, ФГБВОУ ВО «Академия гражданской защиты МЧС России» chis69@mail.ru

Аннотация. Цель работы заключается в том, чтобы с использованием программных средств для моделирования бизнес-процессов и создания моделей базы данных (БД) разработать модели функционирования и БД информационной системы (ИС) управления вычислительными ресурсами корпоративной сети (ВРКС) образовательного комплекса (ОК) Москвы, включающего в свой состав средние общеобразовательные и дошкольные образовательные организации, на базе которого проводилось данное исследование. Результатом проведенного исследования являются разработанные модели функционирования и БД информационной системы, отражающие основные аспекты процесса управления ВРКС образовательного комплекса. Разработанные модели функционирования и БД информационной системы легли в основу дальнейшей разработки прототипа ИС для ОК и позволят в будущем автоматизировать процесс управления BPKC.

Ключевые слова: образовательный комплекс, вычислительные ресурсы, корпоративная сеть, информационная система, модель базы данных, полная атрибутивная модель.

заявок на получение ВР и техническую поддержку, комплектующих изделий для обеспечения работы вычислительной техники заместитель директора ОК по информатизации и сотрудники подразделения информационных технологий ОК пользуются традиционными формами документации, представленной в бумажном и электронном виде разных форматов и извлеченной из разных информационных источников [2]. Следствием этого является несвоевременное и порой ошибочное формирование команд, которые 
должны обеспечивать управление ВРКС в ОК. Заместителю директора ОК по информатизации и сотрудникам подразделения информационных технологий ОК приходится тратить большое количество времени на то, чтобы найти оперативные данные, необходимые для управления ВРКС, что также негативным образом отражается на качестве осуществления стоящих перед ними задач [3].

В работах отечественных и зарубежных исследователей представлены описания научных разработок, посвященных предоставлению вычислительных услуг научным и промышленным предприятиям, а также другим организациям, занимающимся бизнесом. Особую роль в изученных научных источниках играют высокопроизводительные вычисления и суперкомпьютерные технологии, позволяющие выполнять актуальные прикладные и фундаментальные задачи из прогрессивных научных и технических сфер деятельности, для решения которых необходимы огромные мощности вычислительной техники, в частности, связанных с искусственным интеллектом, робототехникой, науками с высоким уровнем использования данных [4].

В научных исследованиях зарубежных исследователей Ding F., Mey D., Wienke S., Zhang R., посвященных проблемам получения доступа к высокопроизводительным ресурсам через облачные сервисы, проанализирован функционал открытых облачных платформ (Amazon, IBM, Google), рассмотрены подходы к применению специальных вычислительных ускорителей для повышения производительности вычислительных комплексов, для увеличения возможностей применения облачных платформ, требующих использования гибридных архитектур построения вычислительных систем.

В научных трудах отечественных исследователей С.М. Абрамова, В.В. Воеводина, С.И. Смагина, Б.Н. Четверушкина, Б.М. Шабанова представлен анализ направлений и подходов к разработке высокопроизводительных вычислительных систем, основанных на гибридных архитектурах, состояния и возможностей суперкомпьютеров из перечня Тор 500, предложена методика объективной оценки производительности вычислительных систем, представленных в данном перечне.

Также этими учеными рассмотрены алгоритмы и инструментальные средства, позволяющие проводить параллельную обработку данных в многомашинных, в т.ч. гибридных системах, а также проблемы виртуализации при облачном подходе к предоставлению сервисов высокопроизводительных вычислений.
Можно сделать вывод, что исследования, проводимые учеными в сфере высокопроизводительных вычислений с использованием гибридных комплексов, являются актуальными.

Также необходимо отметить, что требуют более глубокого изучения такие вопросы, как:

- организация процесса вычислений при синхронном выполнении задач, возникающих в разных областях науки и техники и для решения которых необходима автоматическая или автоматизированная разработка программного кода, осуществляемого в гибридной среде;

- создание настроенной под индивидуальные потребности программной среды реализации;

- разработка методов интеграции с цифровыми платформами.

В работе в качестве объекта исследования рассматриваются бизнес-процессы, отражающие процесс управления ВРКС в ОК, а предметом исследования является процесс проектирования ИС управления ВРКС OK.

Решение задачи проектирования информационной системы управления ВРКС в ОК легло в основу проводимого исследования.

В настоящее время среди существующего специального программного обеспечения отсутствует информационная система, позволяющая комплексно решать поставленные задачи по учету и распределению вычислительных ресурсов в крупной организации. Рассмотрим несколько информационных систем, которые могут решить задачу автоматизации процесса управления вычислительными ресурсами в образовательной организации:

1. ITSM 365 - инструментальное средство, обладающее требующимися функциональными возможностями, позволяющими организациям автоматизировать процессы получения, учета, систематизации, обработки и контроля выполнения пользовательских заявок и обращений.

2. Система IntraService, предназначенная для обеспечения технической поддержки пользователей, включает в свой состав службу ServiceDesk. Благодаря наличию данной службы пользователи системы получают возможность принимать заявки посредством электронной почты, телефона, интерфейса IntraService или путем заполнения специальной формы на web-сайте. Имеется функция, уведомляющая пользователей о появлении новых заявок или о внесении изменений в уже полученные заявки. Один из главных модулей «Заявки и инциденты» включен 


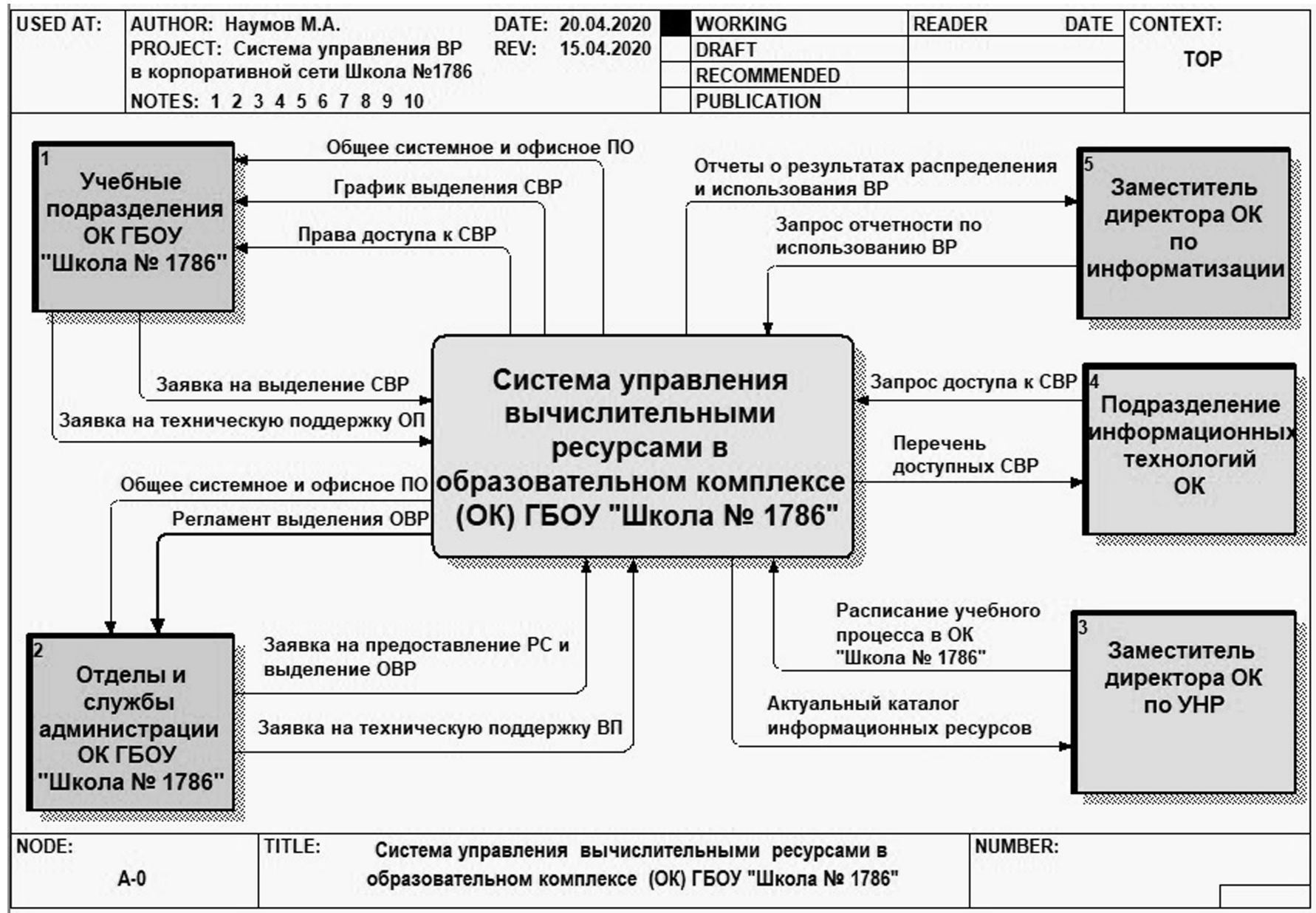

Рис. 1. Контекстная диаграмма верхнего уровня

в состав системы IntraService и позволяет увеличить скорость и привести к определенным стандартам работу с заявками и инцидентами, оперативно контролировать ход их выполнения, вести учет трудовых затрат и формировать отчетные документы.

3. Линейка прикладных решений, работающих на базе технологической платформы 1С: Предприятие 8.3, позволяет автоматизировать организационные и учетные процессы на разных типах предприятий. Эти продукты обладают удобным интерфейсом, инструментами для формирования аналитической отчетности и администрирования системы, средствами для анализа и поиска информации, возможностями к интеграции [5, 6].

4. Программное средство «1C: ITIL Управление информационными технологиями предприятия СТАНДАРТ» предназначено для автоматизации работы ИТ-подразделений организаций и сервисных компаний. Пользователи системы получают возможность управлять работой служб, обеспечивающих техническую поддержку, работать с обращениями клиентов, формировать список сервисов и соглашений о качестве предоставляемых услуг, вести учет оборудования и программного обеспечения.

5. GLPI — русифицированный программный инструмент, работающий на базе СУБД MySQL и позволяющий проводить инвентаризацию компьютерного оборудования и оргтехники. C помощью GLPI можно также организовать службу технической поддержки путем автоматизации процесса обработки сообщений пользователей.

Проведя анализ функциональных возможностей данных систем, можно сделать вывод, что без доработки ни один из рассмотренных инструментов автоматизации не сможет обеспечить комплексное решение проблем, стоящих перед заместителем директора по информатизации образовательного комплекса и сотрудниками подразделения информационных технологий, чья деятельность связана с ведением учета и выде- 


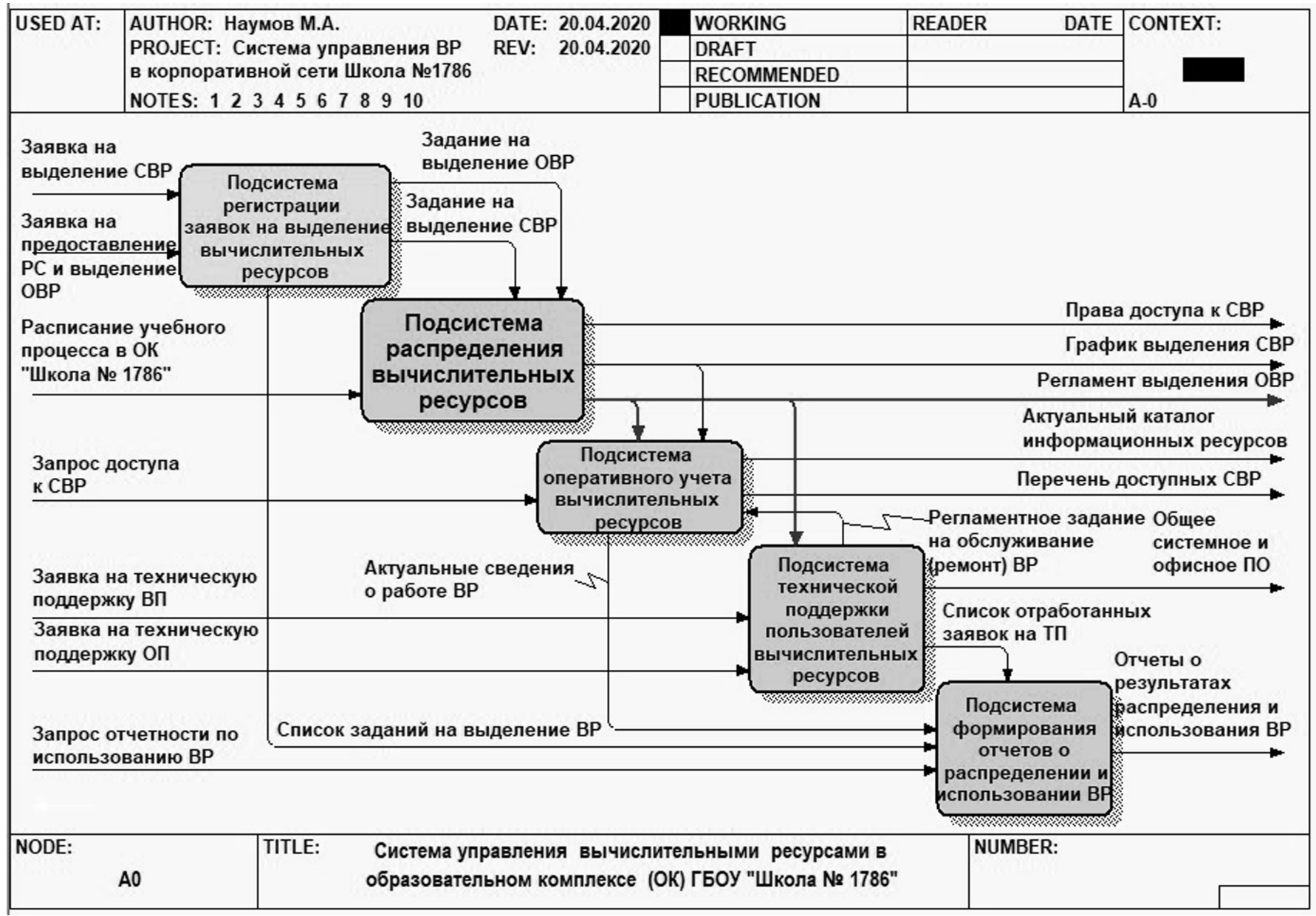

Рис. 2. Контекстная диаграмма уровня А0

лением ВРКС, и требуется разработать новую систему, используя при этом возможности систем, построенных на базе технологической платформы 1С: Предприятие.

На основе проведенного анализа был сформирован перечень функциональных требований, предъявляемых к проектируемой ИС управления ВРКС ОК:

- ведение базы данных по ВР сети, учебным подразделениям ОК, сотрудникам подразделения информационных технологий, а также мероприятиям, связанных с обеспечением технической поддержки пользователей сети ОК;

- автоматизированный учет заявок на выделение ВР сети ОК;

- автоматизированный учет заявок на техническую поддержку пользователей сети ОК;

- автоматизация процессов оперативного учета и распределения вычислительных ресурсов в сети ОК;

- формирование отчетов о результатах распределения и использования вычислительных ресурсов в сети ОК.

\section{Разработка мохели функционирования информационной системы управ^ения вычислительными ресурсами корпоративной сети в образовательном комп^ексе}

Разработка модели функционирования ИС управления ВРКС в образовательном комплексе была выполнена посредством инструментария CA ERWin Process Modeler и методологии DFD [7].

Контекстная диаграмма верхнего уровня, показывающая, каким образом происходит использование ИС управления ВРКС в образовательном комплексе в целом, представлена на рисунке 1.

К основным внешним сущностям, осуществляющим взаимодействие с данной информационной системой, относятся учебные подразделения, отделы и службы администрации, подразделение информационных технологий ОК, заместители директора по информатизации и по УНР. Внешние сущности за- 


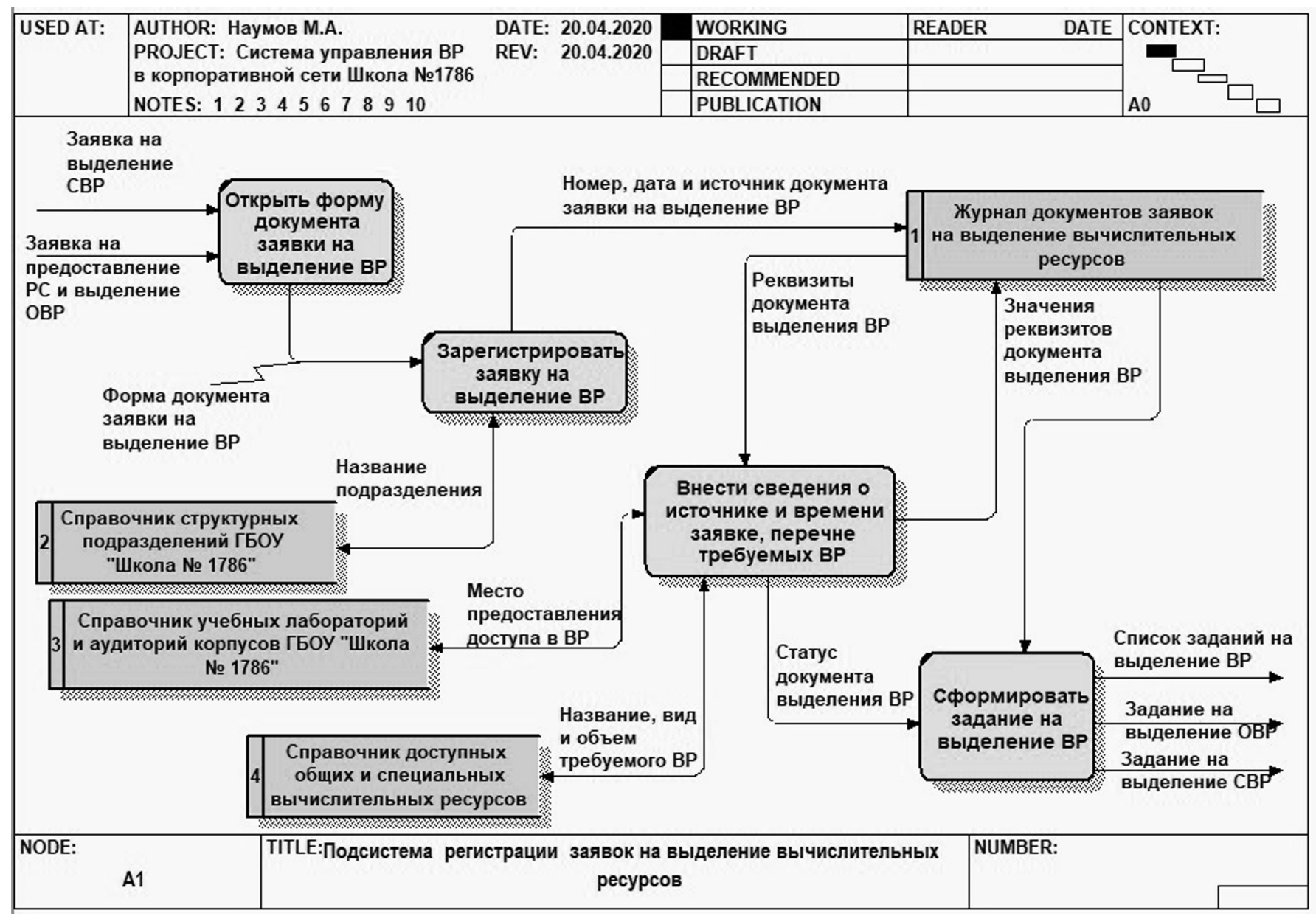

Рис. 3. Диаграмма потоков данных подсистемы регистрации заявок на выделение вычислительных ресурсов

нимаются регистрацией и обработкой заявок на выделение пользователям общих и специальных вычислительных ресурсов (ОВР, СВР) разных видов, а также на получение технической поддержки в процессе организации и осуществления образовательного процесса (ОП). Также в их обязанности входит формирование регламентов и графиков использования ВР, учет разных категорий заявок по их важности, статусу, происхождению, виду, ответственным за выполнение, списку необходимых действий, а также в зависимости от времени, необходимого для того, чтобы устранить имеющуюся неисправность. К функционалу заместителя директора по информатизации также относится формирование отчетов, отражающих полученный эффект в результате проведения работ по выделению и применению ВР.

В дальнейшем основная подсистема «Система управления вычислительными ресурсами в образовательном комплексе (ОК) ГБОУ «Школа 1786» была детализирована. В результате проведенной детализации можно увидеть на рисунке 2 контекстную диаграмму уровня $\mathrm{AO}$.

Было выполнено разбиение центральной подсистемы «Система управления вычислительными ресурсами в образовательном комплексе (ОК) ГБОУ «Школа 1786» на несколько подсистем:

- регистрации заявок на выделение ВР;

- распределения ВР;

- оперативного учета ВР;

- технической поддержки пользователей ВР;

- формирования отчетов о распределении и использовании ВР.

После поступления заявки на регистрацию в системе происходит назначение задания на выделение СВР и ОВР, за выполнение которого отвечает подсистема распределения ВР. При формировании отчетной документации учитываются права доступа пользователей к СВР, график и регламент выделения ресурсов, список возможных СВР. Также в системе обрабатываются за- 
Таблица 1. Описание сущно стей, входящих в состав модели базы данных

\begin{tabular}{|c|c|}
\hline Имя сущности & Характеристика \\
\hline 1 & 2 \\
\hline Подразделение & Содержит данные о подразделениях ОК \\
\hline Место доступа ВР & Хранит данные о местах доступа к вычислительным ресурсам \\
\hline PC & Хранит данные о рабочих станциях \\
\hline Состав PC & Хранит данные о составе рабочих станций \\
\hline Пользователь ВР & Хранит данные о пользователях вычислительных ресурсов \\
\hline Сотрудник ПИТ & Хранит данные о сотрудниках подразделения информационных технологий \\
\hline Расходный материал & Хранит данные о расходных материалах \\
\hline Вычислительный ресурс & Хранит данные о вычислительных ресурсах корпоративной сети образовательного комплекса \\
\hline Характеристика ВР & Хранит данные о характеристиках вычислительных ресурсов \\
\hline Заявка на ВР & Хранит данные о заявках на выделение ВР \\
\hline Состав заявки ВР & Хранит данные о составе заявок на выделение ВР \\
\hline Заявка на ТП & Хранит данные о заявках на обеспечение технической поддержки пользователей \\
\hline Состав заявки ТП & Хранит данные о составе заявок на обеспечение технической поддержки пользователей \\
\hline
\end{tabular}

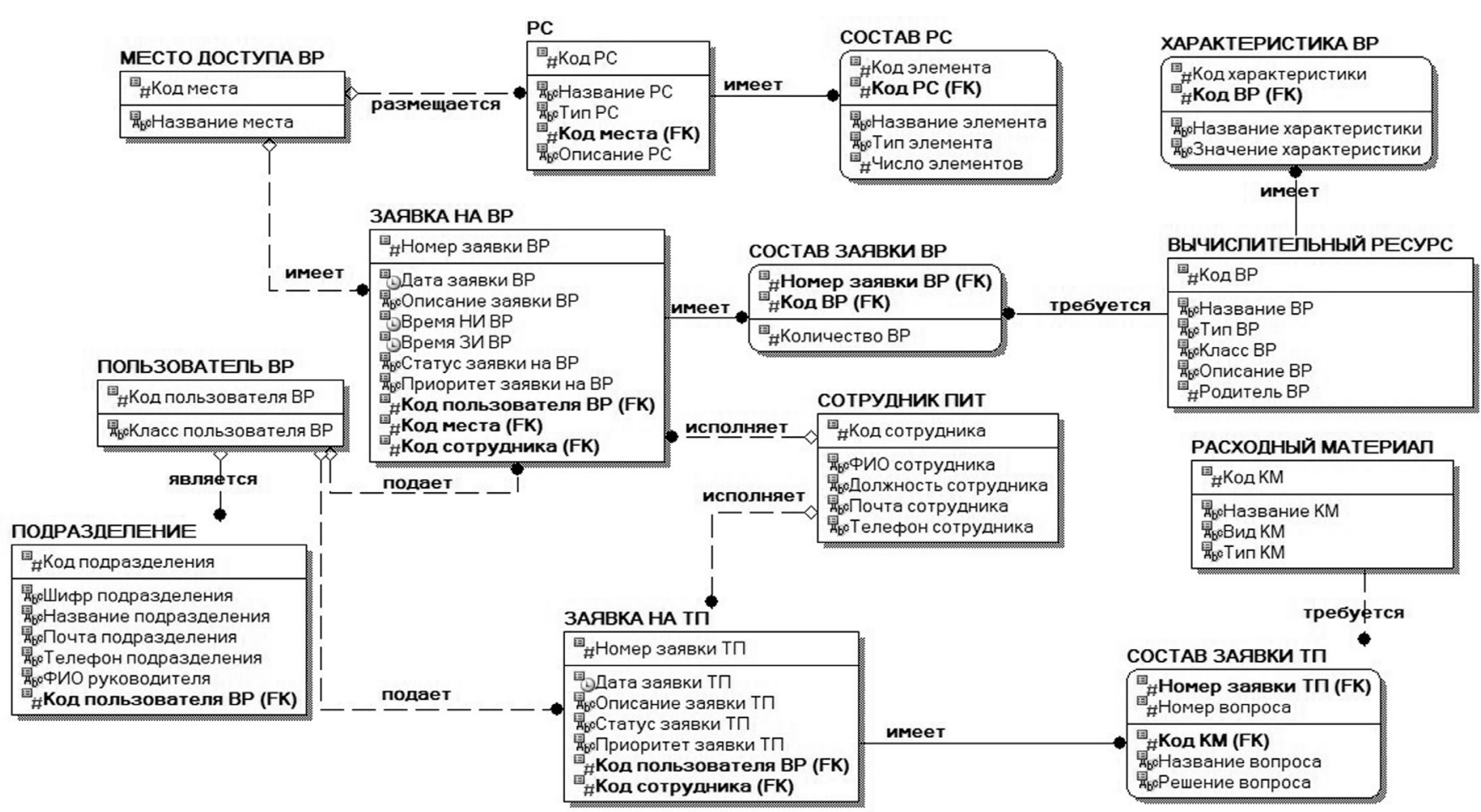

Рис. 4. Полная атрибутивная модель БД ИС для ОК 
явки на обслуживание (ремонт) ВР, для их выполнения необходимо иметь актуальные данные о функционировании ВР. После получения всех необходимых данных происходит формирование отчета, отражающего полученный эффект в результате проведения работ по выделению и применению ВР.

Рассмотрим детализацию подсистемы регистрации заявок на выделение ВР, представленной в виде диаграммы потоков данных на рисунке 3.

Для начала работы с заявкой необходимо произвести открытие шаблона документа, содержащего заказ на предоставление ВР, и осуществить регистрацию данной заявки, далее нужно выполнить ввод данных о происхождении и времени заказа и списке требуемых BP, а также оформить поручение на предоставление BP.

Также на диаграмме потоков данных представлены накопители данных, содержащие необходимую информацию о принятых заявках на предоставление ВР, доступных ОВР и СВР и структурных подразделениях, учебных лабораториях и аудиториях корпусов ГБОУ «Школа № 1786».

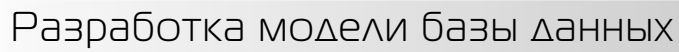 информашионной системы управления ВРКС образовательного комплекса}

Модель БД ИС управления ВРКС ОК реализована посредством использования инструмента CA ERwin Data Modeler. Благодаря данному инструментарию достигается возможность консолидации с CA ERwin Process Modeler для создания схемы данных разрабатываемой системы, основанием для разработки которой выступила спроектированная ранее модель функционирования. Модель, разработанная в среде инструментария CA ERwin Data Modeler, традиционно представляется на двух уровнях: логическом и физическом. На логическом уровне выделяют три вида диаграмм: полная атрибутивная модель, диаграмма сущность-связь и модель данных, основанная на ключах, на физическом уровне представления данных выделяется трансформационная модель БД $[8,9]$.

Таблица 1 содержит информацию о характеристиках сущностей, включенных в состав модели БД ИС управления ВРКС ОК.

Полную атрибутивную модель (FA-модель) БД ИС управления ВРКС ОК можно увидеть на рисунке 4. Отношения на данной диаграмме сводятся к третьей нормальной форме, а содержание модели отражают созданные сущности, реквизиты и отношения, возникающие между ними.

Созданные модели функционирования и БД, отражающие деятельность по автоматизации процесса управления ВРКС ОК, применены в процессе разработки ИС управления ВРКС в ОК.

\section{Зак^ючение}

Авторами проанализированы функциональные возможности представленного на рынке инструментария, позволяющего автоматизировать работы по управлению вычислительными ресурсами корпоративной сети образовательного комплекса. По результатам проведенного обследования объекта автоматизации создана модель функционирования ИС управления ВР корпоративной сети образовательного комплекса.

Создана модель базы данных ИС управления ВРКС OK, служащая основанием для дальнейшего создания прототипа ИС, позволяющей автоматизировать процессы, связанные с управлением вычислительными ресурсами образовательной организации.

\section{ЛИТЕРАТУРА}

1. Ромашкова 0.Н., Ермакова Т.Н. Этапы реализации методики выбора информационной модели для оценки показателей качества обучения // Междисциплинарные исследования в области математического моделирования и информатики Материалы 7-й научно-практической internet-конференции. отв. ред. Ю.С. Нагорнов. — 2016. - С. 318-321.

2. Zverev S., Cardiff J., Stefanovskiy D., Alexandrov M., Catena A., Shushkevich E. Classification of Schoolchildren on Professional Trajectories Using Experience of Successful Specialists//B сборнике: IEEE2019 14th International Scientific and Technical Conference on Computer Sciences and Information Technologies, CSIT 2019 - Proceedings. 14. 2019. C. 215-219.

3. Ромашкова О.Н., Ермакова Т.Н. Мониторинг качества образования в средней общеобразовательной организации с использованием современных средств информатизации // Вестник Российского университета дружбы народов. Серия: Информатизация образования. 2014. C. 10-17.

4. Ромашкова 0.Н., Ермакова Т.Н. Применение инфокоммуникационных технологий для анализа показателей качества обучения образовательного комплекса // В сборнике: Технологии информационного общества. Х Международная отраслевая научно-техническая конференция: сборник трудов. 2016. C. 388-389. 
5. Romashkova, 0.N., Ponomareva, L.A., Chiskidov, S.V. Instrumental implementation of the educational process model to improve the rating of the universities // CEURWorkshop Proceedings 8. Cep."ITTMM 2019 — Proceedings of the Selected Papers of the 8th International Conference "Information and Telecommunication Technologies and Mathematical Modeling of High-Tech Systems"'' 2019. C. 92-101.

6. Ермакова Т.Н., Ромашкова 0.Н. Объединенная информационная модель управления образовательным комплексом // В книге: Информационно-телекоммуникационные технологии и математическое моделирование высокотехнологичных систем. материалы Всероссийской конференции с международным участием. Российский университет дружбы народов. 2015. С. 128-130.

7. Ромашкова 0.Н., Ермакова Т.Н. Моделирование информационных процессов управления образовательным комплексом // Вестник Российского университета дружбы народов. Серия: Информатизация образования. 2014. № 2. С. 122-129.

8. Gaidamaka, Y.V., Romashkova, O.N., Ponomareva, L.A., Vasilyuk, I.P. Application of information technology for the analysis of the rating of university // В сборнике: CEUR Workshop Proceedings 8. Cер. "ITTMM 2018 — Proceedings of the Selected Papers of the 8th International Conference "Information and Telecommunication Technologies and Mathematical Modeling of High-Tech Systems'"' 2018. C. 46-53.

9. Горелов Г.В., Ромашкова 0.Н. Оценка качества обслуживания в сетях с пакетной передачей речи и данных // Вестник Российского университета дружбы народов. Серия: Прикладная и компьютерная математика. 2003. Т. 2. № 1. С. $23-31$.

( ) Наумов Максим Александрович ( manaumoo@yandex.ru ), Ромашкова Оксана Николаевна ( ox-rom@yandex.ru ),

Ермакова Татьяна Николаевна ( ermaktat@bk.ru), Чискидов Сергей Васильевич ( chis69@mail.ru ).

Журнал «Современная наука: актуальные проблемы теории и практики»

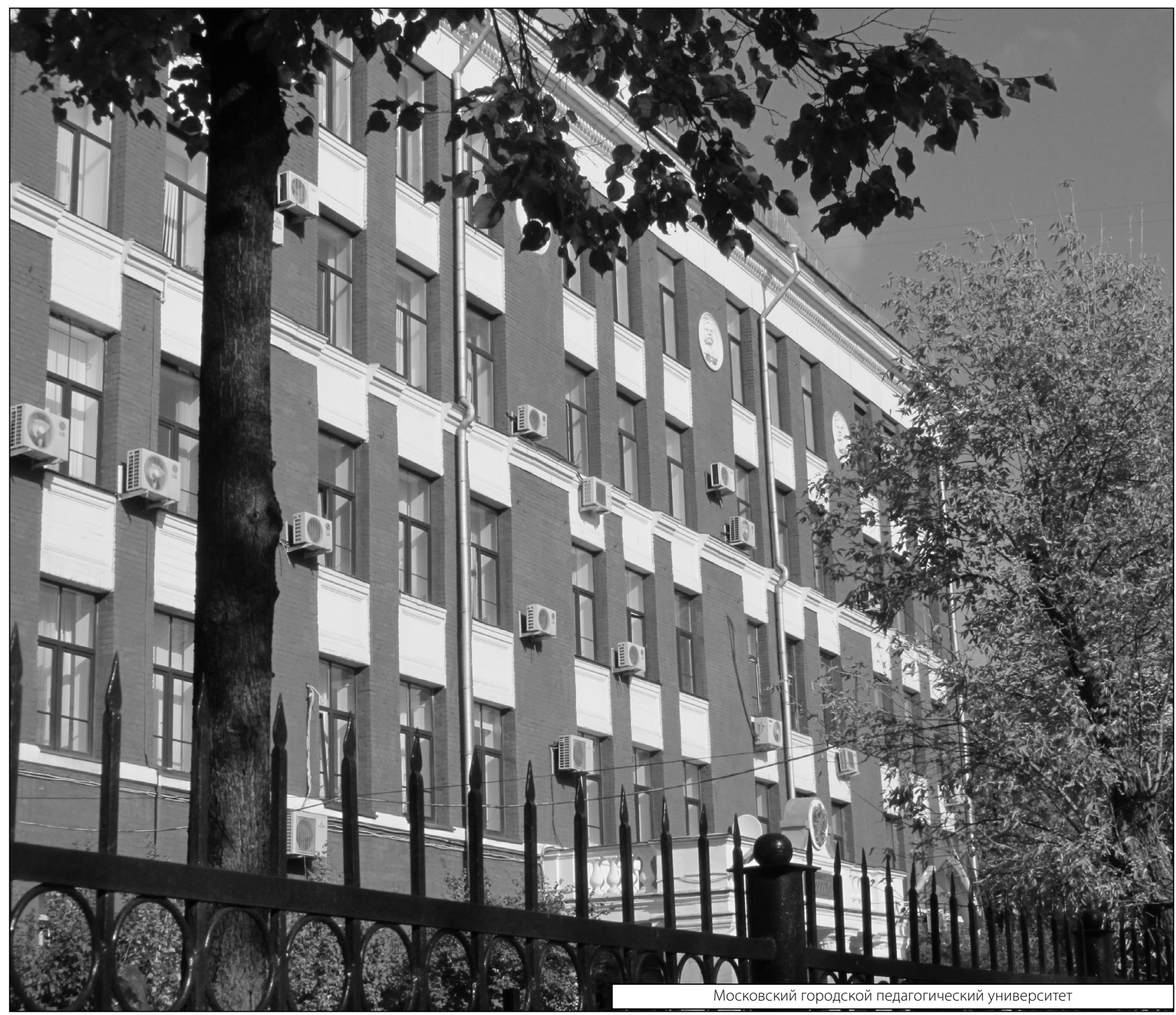

